\title{
On the numerical assessment of the thermal-hydraulic operating map of the DEMO divertor plasma facing components cooling circuit
}

\author{
P. A. Di Maio ${ }^{a^{*}}$, R. Burlon ${ }^{a}$, M. Giardina ${ }^{a}$, J. H. You ${ }^{b}$, G. Mazzone ${ }^{c}$, E. Vallone $^{a}$ \\ ${ }^{a}$ University of Palermo, Department of Engineering, Viale delle Scienze, Edificio 6, 90128 Palermo, Italy \\ ${ }^{b}$ Max Planck Institute of Plasma Physics (E2M), Boltzmann Str.2, 85748 Garching, Germany \\ ${ }^{c}$ Department of Fusion and Technology for Nuclear Safety and Security, ENEA C.R. Frascati, via E. Fermi 45, 00044 \\ Frascati (Roma), Italy
}

Within the framework of the Work Package DIV 1 - "Divertor Cassette Design and Integration" of the EUROfusion action, a research campaign has been jointly carried out by University of Palermo and ENEA to investigate the thermal-hydraulic behaviour of the DEMO divertor cassette cooling system, focussing the attention on the 2018 configuration of the Plasma Facing Components (PFCs) circuit consistent with the DEMO baseline 2017. The research campaign has been carried out following a theoretical-computational approach based on the finite volume method and adopting the commercial Computational Fluid-Dynamic (CFD) code ANSYS CFX.

A steady-state CFD analysis has been carried out for the PFCs cooling circuit under nominal conditions and its thermal-hydraulic performances have been assessed in terms of coolant total pressure drop, flow velocity and Critical Heat Flux (CHF) margin distributions among the Plasma Facing Units (PFUs) channels, to check whether they comply with the corresponding limits. Results obtained have clearly predicted a total pressure drop of $\approx 1.7 \mathrm{MPa}$, slightly higher than the prescribed limit of $1.4 \mathrm{MPa}$, as well as a sufficient margin against CHF onset, higher than 1.4 except for three IVT PFU channels where a minimum value of 1.39 is predicted.

Moreover, a parametric study has been performed in order to assess the operating map of the cooling circuit in the phase-space of coolant inlet temperature, pressure and mass flow rate, to be intended as that domain where the circuit thermal-hydraulic performances let it stay within the prescribed requirements.

Models, loads and boundary conditions assumed for the analyses are herewith reported and critically discussed, together with the main results obtained.

Keywords: DEMO, divertor, plasma facing components, thermofluid-dynamics, CFD analysis.

\section{Introduction}

Within the framework of the activities foreseen by the WP-DIV 1 - "Divertor Cassette Design and Integration" [1] of the EUROfusion action, a research campaign has been launched at University of Palermo in close cooperation with ENEA, to investigate the thermalhydraulic performances of the DEMO divertor Plasma Facing Components (PFCs) cooling circuit $[2,3,4,5,6]$.

Recently, attention has been focussed on the 2018 configuration of this circuit, consistent with DEMO baseline 2017, and its thermal-hydraulic performances have been assessed under nominal steady state conditions to check whether they comply with the total pressure drop requirement $(\Delta \mathrm{p}<1.4 \mathrm{MPa})$, providing a uniform cooling to vertical targets with a viable CHF margin (> 1.4). Moreover, a parametric study has been performed to assess the operating map of the cooling circuit in the phase-space of coolant inlet temperature, pressure and mass flow rate, to be intended as that domain where the circuit thermal-hydraulic performances let it stay within the prescribed requirements.

The research campaign has been performed following a computational approach based on the finite volume method and adopting the ANSYS CFX v.19.2 Computational Fluid-Dynamic (CFD) code, already used or fusion relevant applications $[7,8,9]$. Models and assumptions are herein reported and discussed, together with the main results obtained.

\section{Outline of 2018 DEMO divertor cassette}

According to its 2018 design [10], DEMO divertor is articulated in 48 toroidal cassettes, each composed of a Cassette Body (CB) supporting a Liner and two PFCs, namely an Inner and an Outer Vertical Target (IVT, OVT) (Fig. 1), composed of actively cooled Plasma Facing Units (PFUs) equipped with a Swirl Tape (ST) turbulence promoter.

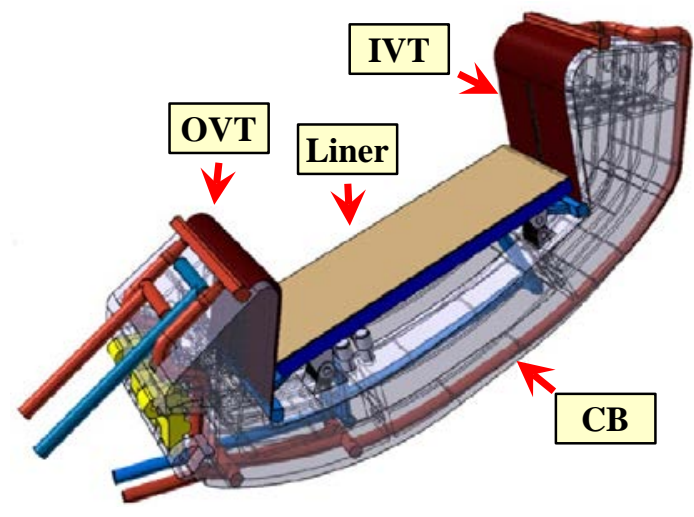

Fig. 1. DEMO divertor cassette 2018 design. 


\section{PFCs cooling circuit}

The 2018 configuration of PFCs cooling circuit has been originated from the reactor segmentation revision occurred with the adoption of DEMO Baseline 2017 and it has been mainly conceived to rearrange the reduced number of cassettes (48 instead of 54) widening their toroidal width and changing their poloidal-radial profile. In particular, the cooling circuit (Fig. 2) is characterised by two main segments, devoted to separately feed coolant to the PFU channels of IVT (31) and OVT (43), connected in parallel by inlet/outlet sharp three-way connections to the inlet/outlet feeding pipes. It relies on the use of subcooled pressurized water at the inlet pressure and temperature of $5 \mathrm{MPa}$ and $130{ }^{\circ} \mathrm{C}$, respectively, flowing under quasi-isothermal conditions. Further details on structural and functional materials may be found in $[6,10,11]$.

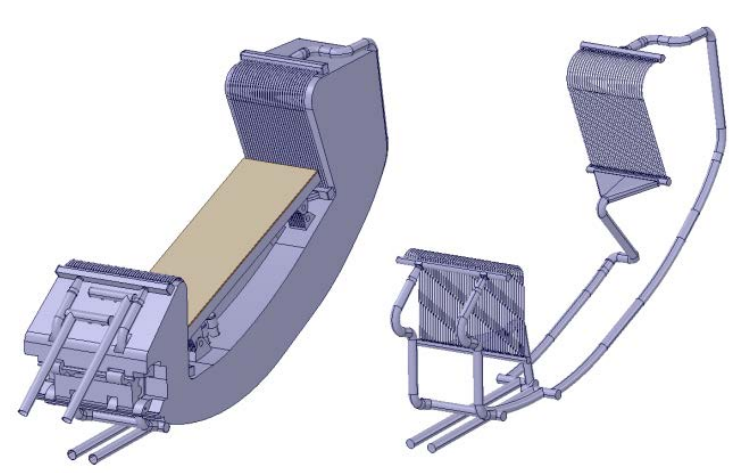

Fig. 2. PFCs cooling circuit 2018 design.

From the hydraulic standpoint, the main changes with respect to the 2017 configuration rely in a larger number of PFUs in the OVT (43 instead of 39), in the revised length and curvature of VT PFU channels, in the deep revision of internal wyes (Fig. 3) and in the change of feeding pipes and internal manifold diameter from 95 $\mathrm{mm}$ to $75 \mathrm{~mm}$ and from $70 \mathrm{~mm}$ to $75 \mathrm{~mm}$, respectively.

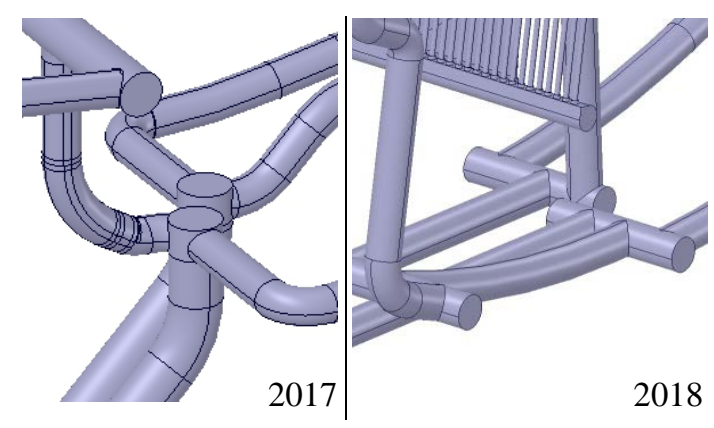

Fig. 3. PFCs cooling circuit main design changes.

These design changes might impact the circuit thermal-hydraulic performances, posing the need for their further investigation, to check whether a uniform VT cooling is still guaranteed with viable CHF margins $(>1.4)$ and total pressure drop $(\Delta \mathrm{p}<1.4 \mathrm{MPa})$.

\section{PFCs cooling circuit CFD analysis}

The thermal-hydraulic behaviour of the 2018 PFCs cooling circuit has been assessed under nominal conditions by running a steady state, isothermal CFD analysis, assuming the coolant operative conditions reported in Table 1. In particular, the coolant has been supposed to flow at the average temperature between those of inlet and outlet sections.

Table 1. Summary of coolant operative conditions.

\begin{tabular}{lc}
\hline & Reference conditions \\
\hline Inlet Pressure [MPa] & 5.0 \\
Inlet Temperature $\left[{ }^{\circ} \mathbf{C}\right]$ & 130 \\
$\Delta \mathrm{T}\left[{ }^{\circ} \mathbf{C}\right.$ ] & 6 \\
Removed Power [MW] & 136 \\
G per Cassette [kg/s] & 98.63 \\
\hline
\end{tabular}

Selected mesh parameters and main assumptions, models and Boundary Conditions (BCs) adopted are reported in Tables 2 and 3, respectively.

Table 2. Summary of selected mesh parameters.

\begin{tabular}{lc}
\hline Nodes & $4.020 \cdot 10^{+7}$ \\
Elements & $5.379 \cdot 10^{+7}$ \\
Inflation Layers Number & 12 \\
First Layer tThickness $[\boldsymbol{\mu m}]$ & 12 \\
Layers Growth Rate & 1.4 \\
Typical Element Size [m] & $2.5 \cdot 10^{-3}$ \\
Surface with $\mathbf{y}+<\mathbf{5 0}[\%]$ & 97 \\
\hline
\end{tabular}

Table 3. Summary of assumptions, models and BCs.

\begin{tabular}{lc}
\hline & Reference conditions \\
\hline Analysis Type & Steady state \\
Material Library & IAPWS IF97 \\
Temperature & $133^{\circ} \mathrm{C}$ \\
Turbulence Model & $\mathrm{k}-\varepsilon$ \\
Boundary Layer Modelling & Scalable wall functions \\
Wall Roughness & $2 \mu \mathrm{m}$ \\
Inlet BC (Static Pressure) & $5 \mathrm{MPa}$ \\
Outlet BC (Mass Flow Rate) & $98.63 \mathrm{~kg} / \mathrm{s}$ \\
\hline
\end{tabular}

\subsection{Results}

The coolant total pressure spatial distribution within the PFCs cooling circuit is reported in Fig. 4, while the total pressure drops across the main sections of the circuit are reported in Table 4. The PFCs cooling circuit overall total pressure drop amounts to $\approx 1.7 \mathrm{MPa}$, exceeding the limit of 1.4 MPa, mainly due to the change of internal wyes, to the reduced diameter of inlet/outlet manifolds, to the increased length of IVT PFU channels and to the higher mass flow rate fed to the OVT circuit. 


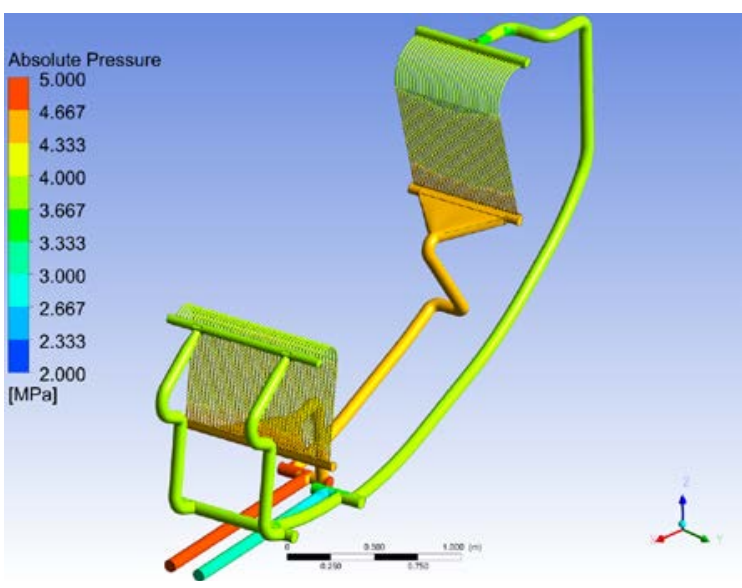

Fig. 4. Total pressure field.

Table 4. Total pressure drops.

\begin{tabular}{lc}
\hline Sections & $\Delta \mathrm{p}[\mathrm{MPa}]$ \\
\hline Inlet Common Manifold & 0.0489 \\
Inlet IVT wye & 0.2705 \\
Inlet IVT Manifold & 0.0213 \\
IVT & 0.8937 \\
Outlet IVT Manifold & 0.0285 \\
Outlet IVT Wye & 0.4316 \\
IVT Circuit Total (no wyes) & $\mathbf{0 . 9 4 3 5}$ \\
Inlet OVT Wye & 0.2555 \\
Inlet OVT Manifold & 0.0550 \\
OVT & 0.7591 \\
Outlet OVT Manifold II & 0.1121 \\
Outlet OVT Wye & 0.4640 \\
OVT Circuit Total (no wyes) & $\mathbf{0 . 9 2 6 2}$ \\
Outlet Common Manifold & 0.0047 \\
PFCs Circuit TOTAL & $\mathbf{1 . 6 9 9 3}$
\end{tabular}

It has to be stressed that, except for VTs, most of the total pressure drop $(\approx 0.7 \mathrm{MPa})$ is located at wyes allowing VTs branching, where the design changes have induced deep differences in the flow field between the present and the previous configuration (Figs. 5-6).

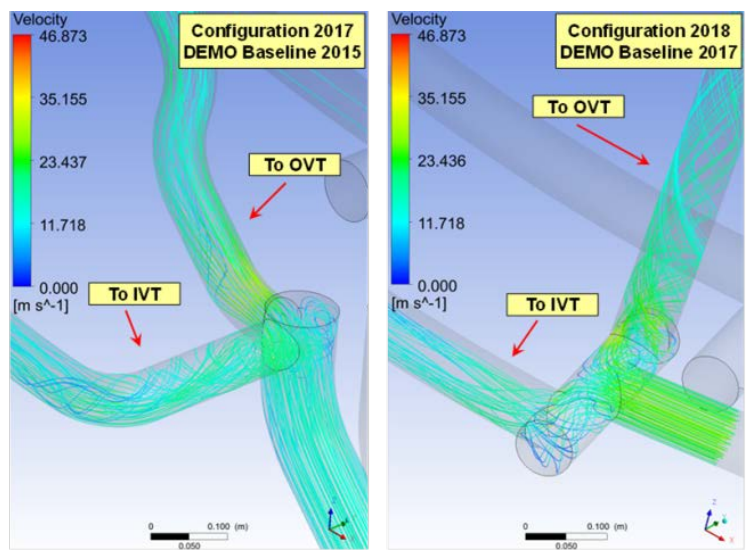

Fig. 5. Inlet wye velocity streamlines.
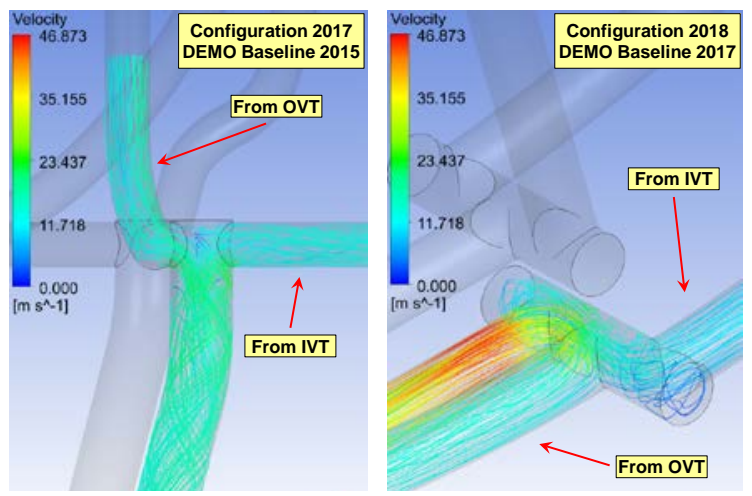

Fig. 6. Outlet wye velocity streamlines.

In particular, the pressure drops calculated across these wyes for the configuration 2017 amount to $\approx 0.05 \div 0.06 \mathrm{MPa}$ for the inlet wyes and to $\approx 0.04 \div 0.06$ $\mathrm{MPa}$ for the outlet ones. They increase up to $\approx 0.26 \div 0.27$ $\mathrm{MPa}$ and to $\approx 0.43 \div 0.46 \mathrm{MPa}$, respectively, posing, hence, the need for a deep revision of the wyes design.

Attention has been paid also to the section-averaged values of coolant axial flow velocity $\left(\mathrm{v}_{\mathrm{ax}}\right)$ within the PFU channels of both VTs in order to check whether the bypass effect across horizontal headers induced by their inlet/outlet manifolds (Fig. 7) might induce a nonuniform cooling of the PFU solid structures endangering their thermo-mechanical performances. In particular, the distributions of $\mathrm{v}_{\mathrm{ax}}$ among the VTs PFU channels are shown in Fig. 8 and their key-parameters have been reported in Table 5.

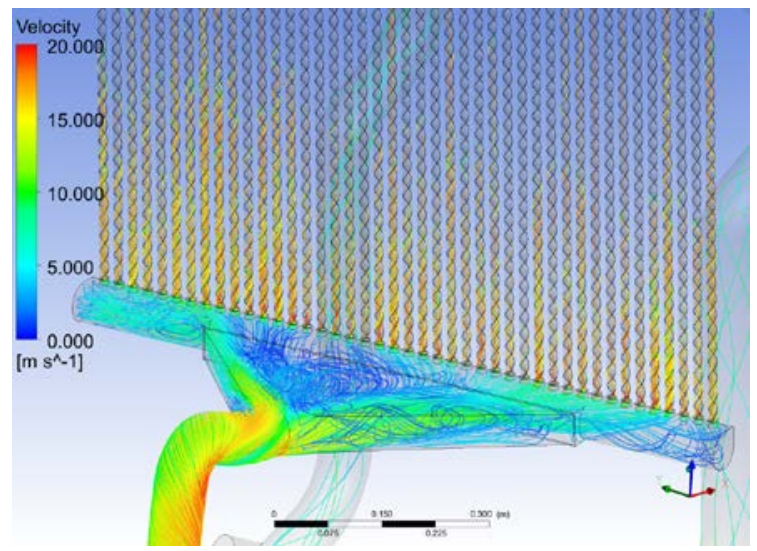

Fig. 7. Velocity streamlines at OVT inlet region.

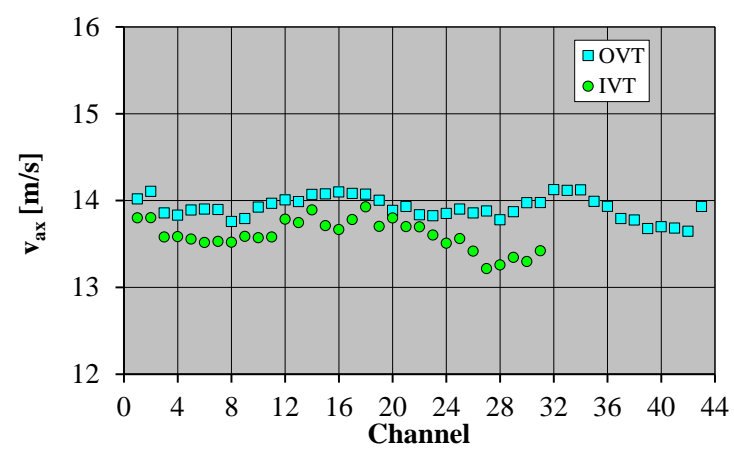

Fig. 8. $v_{\mathrm{ax}}$ distribution among PFU channels. 
Table 5. $\mathrm{v}_{\mathrm{ax}}$ distribution key-parameters.

\begin{tabular}{lcc}
\hline & OVT & IVT \\
\hline $\mathbf{M a x ~ v a x ~}_{\mathbf{a x}}[\mathbf{m} / \mathbf{s}]$ & 14.125 & 13.927 \\
$\mathbf{M i n ~ v}_{\mathbf{a x}}[\mathbf{m} / \mathbf{s}]$ & 13.676 & 13.215 \\
$\boldsymbol{\varepsilon}_{\text {Max-Min }}$ & $3.17 \%$ & $5.11 \%$ \\
Average vax $_{\mathbf{a}}[\mathbf{m} / \mathbf{s}]$ & 13.934 & 13.602 \\
$\boldsymbol{\sigma}[\mathbf{m} / \mathbf{s}]$ & 0.117 & 0.180 \\
\hline
\end{tabular}

From the analysis of the results obtained, it may be argued that within the PFU channels of each VT the distribution of $\mathrm{v}_{\mathrm{ax}}$ is acceptably uniform, since maximum deviations lower than $5.5 \%$ have been estimated between the maximum ( $\mathrm{Max}_{\mathrm{ax}}$ ) and minimum (Min $\mathrm{v}_{\mathrm{ax}}$ ) values.

The distributions of the margin against CHF onset within VTs PFU channels have been assessed to check if the minimum value of 1.4 is guaranteed. Attention has been paid to the strike point sections of VTs, where the peak heat flux from plasma (20 MW/m ${ }^{2}$ [3]) has been supposed to be located. In these sections, adopting the procedure reported in [5] and the correlation of [12], the $\mathrm{CHF}$ at the interface between coolant and channel walls has been calculated for each PFU channel. The distributions obtained have been reported in Fig. 9 and their key-parameters have been summarized in Table 6.

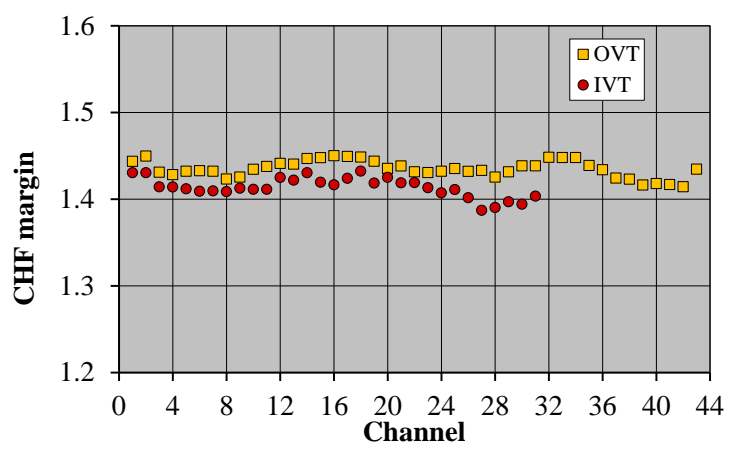

Fig. 9. CHF margin distribution among PFU channels.

Table 6. CHF margin distribution key-parameters.

\begin{tabular}{lcc}
\hline & OVT & IVT \\
\hline Max CHF Margin & 1.450 & 1.432 \\
Min CHF Margin & 1.416 & 1.387 \\
$\boldsymbol{\varepsilon}_{\text {Max-Min }}$ & $2.33 \%$ & $3.16 \%$ \\
Average CHF Margin & 1.436 & 1.414 \\
$\sigma$ & 0.009 & 0.012 \\
\hline
\end{tabular}

Results obtained indicate that the CHF margin distributions are acceptably uniform, since deviations between their maximum and minimum values are lower than $3.5 \%$. Moreover, the average value of the margin calculated for both VTs PFU channels results higher than the prescribed limit of 1.4. The margin is predicted to be lower than 1.4 only in three IVT PFU channels, its lowest value (1.39) occurring at IVT PFU channel \#27.

\subsection{Conclusions}

The CFD analysis of the PFCs cooling circuit thermal-hydraulic performances under nominal steadystate conditions has allowed to conclude that:

- total pressure drop amounts to $\approx 1.7 \mathrm{MPa}$, being higher than the prescribed limit (1.4 MPa), mainly due to the inlet/outlet wyes concentrated hydraulic resistance;

- flow velocity distributions within PFU channels are acceptably uniform, with deviations between maximum and minimum values lower than $6 \%$;

- CHF margin distributions within PFU channels are quite uniform, with deviations between maximum and minimum values lower than $3.5 \%$;

- CHF margin is predicted to be lower than 1.4 only in three IVT PFU channels, its lowest value (1.39) occurring at IVT PFU channel \#27.

The need is, hence, posed to revise the PFCs cooling circuit lay-out to improve its thermal-hydraulic performances, focussing the attention on the inlet/outlet wyes configuration.

\section{Thermal-hydraulic operating map}

A parametric study has been performed in order to assess the operating map of the PFCs cooling circuit in the phase-space of coolant inlet temperature $\left(T_{i n}\right)$, pressure $\left(\mathrm{p}_{\text {in }}\right)$ and mass flow rate $(\mathrm{G})$, to be intended as that domain where the circuit thermal-hydraulic performances stay within the prescribed design requirements, namely pressure drop lower than $1.4 \mathrm{MPa}$ and CHF margin higher than 1.4.

To this purpose, the coolant has been assumed to undergo a quasi-isobaric steady state flow along the PFCs cooling circuit and, adopting a lumped parameter approach, its thermal-hydraulic performances have been assessed mainly in terms of average and outlet temperatures, total pressure drop and CHF margin.

In order to find the coolant thermal performances, it has been observed that, in the assumed conditions, its energy transport equation integrated between inlet and outlet sections reduces to:

$$
\mathrm{W}=\mathrm{Gc}_{\mathrm{p}}(\mathrm{T}, \mathrm{p})\left[\mathrm{T}_{\text {in }}-\mathrm{T}_{\text {out }}\right]
$$

where $\mathrm{W}$ is the total heat power deposited into PFCs to be extracted by the coolant and $c_{p}(T, p)$ is its heat capacity under isobaric conditions, depending on temperature and pressure.

Observing that the envisaged coolant temperature variation is quite modest (up to few tens of degrees) and neglecting the dependence on pressure of water thermophysical properties, it may be concluded that:

$$
\mathrm{c}_{\mathrm{p}}(\mathrm{T}, \mathrm{p}) \approx \mathrm{c}_{\mathrm{p}}\left(\hat{\mathrm{T}}, \mathrm{p}_{\text {in }}\right)
$$

where $\hat{\mathrm{T}}$ is the average temperature of coolant between inlet and outlet sections. Therefore, from Eq.s (1) and 2, it can deduced that the coolant average temperature may 
be found as the root of the following implicit equation:

$$
c_{p}\left(\hat{T}, p_{i n}\right)\left[\hat{T}-T_{i n}\right]=\frac{W}{2 G}
$$

resulting to be dependent on $T_{i n}$, $p_{\text {in }}$ and $G$ and allowing to derive the coolant outlet temperature as follows:

$$
\mathrm{T}_{\text {out }}\left(\mathrm{T}_{\mathrm{in}}, \mathrm{p}_{\text {in }}, \mathrm{G}\right)=2 \hat{\mathrm{T}}\left(\mathrm{T}_{\mathrm{in}}, \mathrm{p}_{\text {in }}, \mathrm{G}\right)-\mathrm{T}_{\text {in }}
$$

Moreover, in order to assess the coolant hydraulic performances, the pressure drop between inlet and outlet sections has been assumed to have the following form:

$$
\Delta p\left(\hat{T}, p_{\text {in }}, G\right)=\frac{K}{2 A^{2} \rho\left(\hat{T}, p_{\text {in }}\right)} G^{2}
$$

where $\rho$ is the coolant density, depending on the average temperature and on the inlet pressure, $\mathrm{K}$ is the effective concentrated hydraulic loss coefficient and $\mathrm{A}$ is the feeding pipe section area. As the coolant average temperature depends on $T_{\text {in }}, p_{\text {in }}$ and $G$, according to Eq. (3), it may be shown that the $\Delta \mathrm{p}$ may be expressed as:

$$
\Delta \mathrm{p}\left(\mathrm{T}_{\mathrm{in}}, \mathrm{p}_{\text {in }}, \mathrm{G}\right)=\alpha\left(\mathrm{T}_{\mathrm{in}}, \mathrm{p}_{\mathrm{in}}, \mathrm{G}\right) \mathrm{G}^{2}
$$

where:

$$
\alpha\left(T_{\text {in }}, p_{\text {in }}, G\right)=\frac{K}{2 A^{2} \rho\left[\hat{T}\left(T_{\text {in }}, p_{\text {in }}, G\right), p_{\text {in }}\right]}
$$

Therefore, once it has been assessed for a given $\mathrm{T}_{\mathrm{in}}{ }^{*}$ temperature, it may be easily extrapolated to other inlet coolant conditions as follows:

$$
\Delta p\left(T_{\text {in }}, p_{\text {in }}, G\right)=\frac{\rho\left[\hat{T}\left(T_{\text {in }}^{*}, p_{\text {in }}, G\right), p_{\text {in }}\right]}{\rho\left[\hat{T}\left(T_{\text {in }}, p_{\text {in }}, G\right), p_{\text {in }}\right]} \alpha\left(T_{\text {in }}^{*}, p_{\text {in }}, G\right) G^{2}
$$

allowing the coolant pressures at the outlet, $\mathrm{p}_{\text {out }}$, and at the strike point, $\mathrm{p}_{\mathrm{sp}}$, roughly assumed coincident with the average total pressure, to be put in the following forms:

$$
\begin{aligned}
& p_{\text {out }}\left(T_{\text {in }}, p_{\text {in }}, G\right)=p_{\text {in }}-\Delta p\left(T_{\text {in }}, p_{\text {in }}, G\right) \\
& p_{\text {sp }}\left(T_{\text {in }}, p_{\text {in }}, G\right)=p_{\text {in }}-\frac{1}{2} \Delta p\left(T_{\text {in }}, p_{\text {in }}, G\right)
\end{aligned}
$$

Finally, the coolant average axial velocity along PFU channels has been determined as follows:

$$
\hat{V}_{i}\left(T_{i n}, p_{i n}, G\right)=\frac{G_{i}}{A N_{i} \rho\left[\hat{T}\left(T_{\text {in }}, p_{\text {in }}\right), p_{\text {in }}\right]}
$$

where index i identifies the VT (IVT or OVT), A is the PFU channel area and $N_{i}$ and $G_{i}$ represent PFUs number and mass flow rate of the i-th VT, respectively.

Once the coolant average axial velocity in each VT has been computed as a function of $T_{\text {in }}, p_{\text {in }}$ and $G$, the corresponding CHF margin has been derived for both the VTs, according to the same procedure indicated in $\S 4.1$. The minimum CHF margins for both VTs have been conservatively assumed as the $95 \%$ of these values.
A parametric study has been carried out assuming $\mathrm{T}_{\text {in }}$ values ranging between $80^{\circ} \mathrm{C}$ and $200{ }^{\circ} \mathrm{C}$, along with $p_{\text {in }}$ values of $5 \mathrm{MPa}$ (reference), $6 \mathrm{MPa}$ and $7 \mathrm{MPa}$ and $\mathrm{G}$ values amounting to $70 \mathrm{~kg} / \mathrm{s}, 80 \mathrm{~kg} / \mathrm{s}, 98.63 \mathrm{~kg} / \mathrm{s}$ (reference) and $110 \mathrm{~kg} / \mathrm{s}$. Moreover, a pressure drop of 1.4 MPa under the reference conditions of $\mathrm{T}_{\mathrm{in}}{ }^{*}=130^{\circ} \mathrm{C}$ and $\mathrm{P}_{\text {in }}=5 \mathrm{MPa}$ has been considered as reasonably attainable by the suggested design revision.

\subsection{Results}

According to previous equations, the coolant overall thermal rise, its outlet temperature, its pressure drop and the minimum CHF margin within the PFU cooling channels have been calculated and they have allowed the operating maps reported in Figs. 10-12 to be obtained.

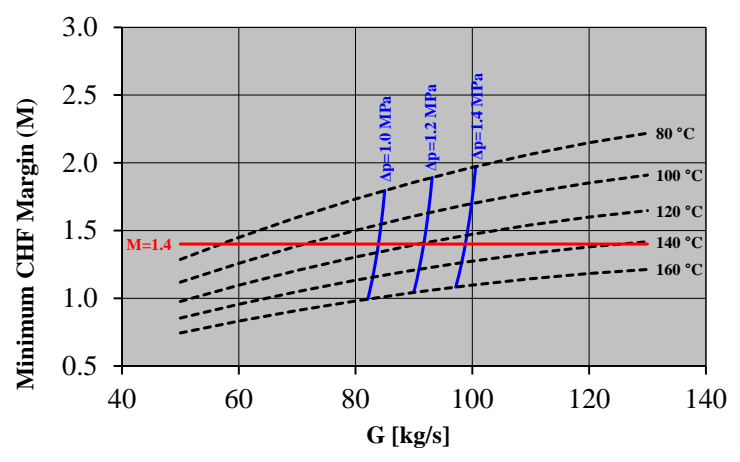

Fig. 10. Minimum OVT CHF margin (M) vs $\mathrm{G}$ at $\mathrm{p}_{\mathrm{in}}=5 \mathrm{MPa}$.

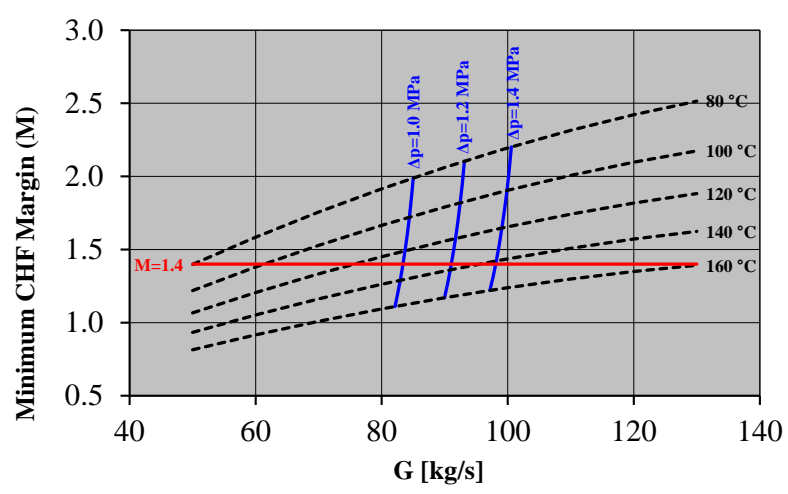

Fig. 11. Minimum OVT CHF margin (M) vs $G$ at $p_{\text {in }}=6 \mathrm{MPa}$.

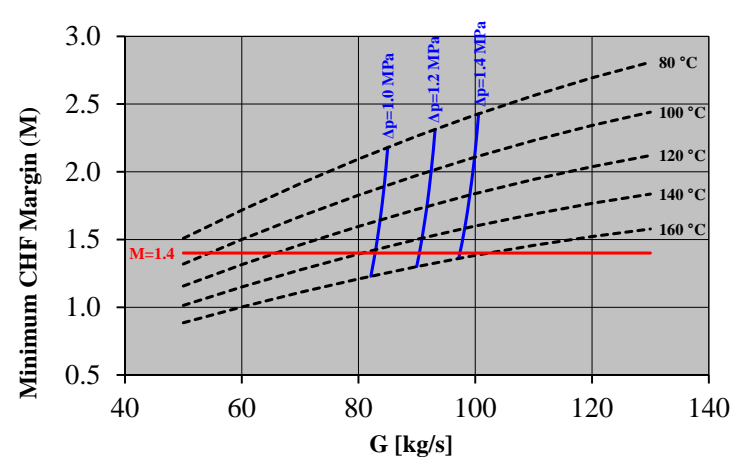

Fig. 12. Minimum OVT CHF margin (M) vs $G$ at $p_{i n}=7 \mathrm{MPa}$. 
As to the PFCs cooling circuit hydraulic performances, it has to be underlined that the total pressure drop is an increasing function of both coolant mass flow rate and inlet temperature, resulting practically unaffected by the inlet pressure of the coolant as a consequence of its quasi-incompressible behaviour. In particular, from the operating maps reported in Figs. 10-12 it is possible to concluded that, in order to comply with the maximum pressure drop of $1.4 \mathrm{MPa}$, the coolant mass flow rate has to be lower than $98 \div 100 \mathrm{~kg} / \mathrm{s}$ when the inlet temperature varies from $160^{\circ} \mathrm{C}$ down to $80^{\circ} \mathrm{C}$.

As to the PFCs cooling circuit thermal performances, it can be deduced that the minimum CHF margin is an increasing function of mass flow rate and a decreasing function of inlet temperature, being deeply affected by inlet pressure of coolant as a consequence of the strong dependence of its vaporization enthalpy and saturation temperature on its static pressure. In particular, from the operating maps (Figs. 10-12) it is possible to observe that, in order to meet the minimum CHF margin of 1.4, while complying with the pressure drop requirement, the coolant inlet temperature has to be lower than $140 \div 160^{\circ} \mathrm{C}$, depending on the inlet pressure value.

In conclusion, the operating domain of the PFCs cooling circuit is composed, for a given inlet pressure, by all the points characterized by a CHF higher than the limit (red curve in Figs. 10-12) and a mass flow rate and an inlet temperature that collocate them on the left of the pressure drop limit curve (blue curve in Figs. 10-12). A comparison of the operating maps relevant to the different inlet pressures considered, allows to conclude that the higher is the coolant inlet pressure, the wider is the pertaining PFCs cooling circuit operating domain.

\section{Conclusions}

Within the framework of the EUROfusion action, a research campaign has been carried out by University of Palermo and ENEA to study the thermal-hydraulic behaviour of DEMO divertor cassette cooling system, focussing the attention on the PFCs cooling circuit 2018 configuration. A theoretical-computational approach based on the finite volume method has been followed and the ANSYS CFD code has been adopted.

The PFCs cooling circuit nominal thermal-hydraulic performances have been assessed in terms of coolant total pressure drop, flow velocity and CHF margin distributions. The results obtained have indicated a total pressure drop higher than the prescribed limit and amounting to $\approx 1.7 \mathrm{MPa}$, mainly due to the inlet/outlet wyes hydraulic resistance, acceptably uniform flow velocity and CHF margin distributions within the PFU channels and the occurrence of a CHF margin slightly lower than 1.4 (1.39) only in three IVT PFU channels. A proper revision of the cooling circuit lay-out, mainly focussed onto inlet/outlet wyes, is, hence, encouraged to improve its thermal-hydraulic performances.

Moreover, a parametric study has been performed, to assess the PFCs cooling circuit operating map in the phase-space of coolant inlet temperature, pressure and mass flow rate. It has allowed to conclude that, in order to comply with the maximum pressure drop requirement, mass flow rate has to has to be lower than $98 \div 100 \mathrm{~kg} / \mathrm{s}$ with inlet temperatures ranging from $160^{\circ} \mathrm{C}$ to $80^{\circ} \mathrm{C}$, while in order to meet also the minimum $\mathrm{CHF}$ margin, the inlet temperature has to be lower than $140 \div 160^{\circ} \mathrm{C}$, according to the inlet pressure value.

\section{Acknowledgments}

This work has been carried out within the framework of the EUROfusion Consortium and has received funding from the Euratom research and training programme 2014-2018 and 2019-2020 under grant agreement No 633053. The views and opinions expressed herein do not necessarily reflect those of the European Commission.

\section{References}

[1] J.H. You, et al., Progress in the initial design activities for the European DEMO divertor: Subproject "Cassette", Fusion Eng. Des. 124 (2017) 364-370.

[2] P.A. Di Maio, S. Garitta, J.H. You, G. Mazzone, E. Vallone, Thermal-hydraulic behaviour of the DEMO divertor plasma facing components cooling circuit. Fusion Eng. Des. 124 (2017) 415-419.

[3] P.A. Di Maio, S. Garitta, J.H. You, G. Mazzone, E. Vallone, On the thermal-hydraulic optimization of DEMO divertor plasma facing components cooling circuit, Fusion Eng. Des. 136 (2018) 1438-1443.

[4] P.A. Di Maio, S. Garitta, G. Mazzone, E. Vallone, DEMO Divertor - Thermo-hydraulic assessment report 2017, IDM Ref. EFDA_D_2MR3LR.

[5] P.A. Di Maio, S. Garitta, J.H. You, G. Mazzone, E. Vallone, Hydraulic analysis of EU-DEMO divertor plasma facing components cooling circuit under nominal operating scenarios, Fusion Eng. Des., https://doi.org/10.1016/j.fusengdes.2019.03.030.

[6] P.A. Di Maio, M. Giardina, G. Mazzone, E. Tomarchio, E. Vallone, Cassette concept design development - 2nd phase thermo-hydraulic assessment (including shielding liner). IDM Ref. EFDA_D_2NEM88 v1.0.

[7] P.A. Di Maio et al., Analysis of the steady state hydraulic behaviour of the ITER blanket cooling system, Fusion Eng. Des. 98-99 (2015) 1470-1473.

[8] P.A. Di Maio et al., Numerical simulation of the transient thermal-hydraulic behaviour of the ITER blanket cooling system under the draining operational procedure, Fusion Eng. Des. 98-99 (2015) 1664-1667.

[9] P.A. Di Maio et al., On the hydraulic behaviour of ITER Shield Blocks \#14 and \#08. Computational analysis and comparison with experimental tests, Fusion Eng. Des. 109-111 (2016) 30-36.

[10] D. Marzullo, C. Bachmann, D. Coccorese, G. Di Gironimo, P. Frosi, G. Mazzone, J.H. You, Progress in the pre-conceptual CAD engineering of European DEMO divertor cassette, Fusion Eng. Des. 146 (2019) 942-945.

[11] P. Frosi et al., WPDIV-1-T005 Loads Specification (LS) for Divertor Cassette 2018 (incl. neutronics, EM analysis), IDM Ref. EFDA_D_2NLWLE v1.0.

[12] A.R. Raffray et al., Critical heat flux analysis and R\&D for the design of the ITER divertor, Fusion Eng. Des. 45 (1999) 377-407. 